\title{
The problem of shelf-warmers in electronic commerce: a proposed solution
}

\section{Grzegorz Chodak ${ }^{1}$ (1)}

Received: 21 February 2020 / Revised: 23 May 2020 / Accepted: 28 June 2020 / Published online: 7 July 2020 (c) The Author(s) 2020

\begin{abstract}
This paper presents the significant problem of so called shelf-warmers in the environment of electronic commerce. In the first part of the paper, the factors that have led to an increasing stock of shelf-warmers in online stores are discussed. These factors are divided into two groups: those that occur mainly in an online store environment and those not specifically associated with an online environment. One group of factors are related to the large number of items offered in an online store enabled by various models of inventory management (e.g. drop-shipping, 3PL, 4PL), the lack of a need to maintain costly space for the exposition of goods, the heterogeneity of online shoppers and the large number of returns from customers. The other group of factors concern incorrect forecasts of demand, inappropriate inventory control, choice of product assortment, pricing policies and the end of a product's life cycle. The problem of appropriately identifying shelf-warmers is then discussed and an index measuring the tendency of a good to be a shelf-warmer is proposed. Based on this, different methods for dealing with shelf-warmers are outlined in the form of the use of recommendation systems, search engine optimization and social media. The paper then presents an experiment conducted in a real business environment to assess the effectiveness of some of the aforementioned methods. This experiment resulted in the sale of approximately $33 \%$ of 160 selected shelf-warmers and over $50 \%$ from one group (number 8 ) where all the suggestions were implemented, within a period of 10 months. The results obtained show that the methods and recommendations proposed may help online stores to deal with the problem of shelf-warmers.
\end{abstract}

Keywords E-commerce $\cdot$ Inventory control $\cdot$ Online store $\cdot$ Shelf-warmer $\cdot$ Slow moving products $\cdot$ Search engine optimization $(\mathrm{SEO}) \cdot$ Social media

Grzegorz Chodak

grzegorz.chodak@pwr.edu.pl

1 Department of Operational Research and Business Intelligence, Wroclaw University

of Technology, Wybrzeze Wyspiańskiego 27, 50-370 Wrocław, Poland 


\section{Introduction}

The development of electronic commerce during the last two decades has changed the retail trade. Among online stores, there are both global corporations, such as Amazon.com, and small, niche online stores. Both types of enterprise face the problem of unsold products, which generate storage costs, as well as freezing capital.

In the literature concerning the management of online stores, many publications have analysed aspects such as: recommendation systems, social marketing, search engine optimization (SEO), but only a few publications have analysed the problem of inventory control. There is also a research gap concerning the problem of slow moving products in e-commerce.

An online store, even a small one, can offer a wide range of products, due to a two-step transaction process. In the first step, the customer places an order. In the second step, the order is carried out. It should be noted that the second step may occur after some time (even after a few weeks in some cases). A wide assortment may lead to an increasing stock of slow moving products, which are sold only at a very slow rate or even not at all. Such products are named "shelf-warmers", as they lie on inventory shelves for a long time. In the context of the Internet, the noun shelf-warmer is a "colloquial term for a toy or product that either fails to sell well or is over-produced, leaving residual quantities on store shelves for months or even years after its original release" (Transformers Wiki - Definition of Shelf-warmer). In the literature, such products are usually named slow moving items (Croston 1974; Williams 1983) or slow moving inventories (Snyder 2002). However, in this paper we use the term shelf-warmers to emphasize that these products not only have a low turnover, but some of them are even never sold. The categorization of goods into slow moving goods and shelf-warmers is crucial, because it affects sales policy (Jollyta et al. 2019) and inventory management.

The amount of capital frozen increases as the stock of shelf-warmers grows, since inventory turnover decreases. Consequently, it is very important to identify such products, in order to optimize inventory, liquidity and activity ratios (Gaur et al. 2005).

The main aim of this paper is to propose methods for detecting shelf-warmers in an online store. The second aim is to propose methods for decreasing the stock of shelf-warmers in an online store. The third aim is to assess some of these methods in a real business environment. The proposed methods are a contribution to the theory of logistics, as well as being important for business practice, because they enable e-stores to reduce inventory costs and therefore increase profits. Another contribution to management practice is the presentation of an experiment carried out in a real business environment, which is rare in the e-commerce literature.

The structure of this paper is as follows: firstly, the key factors leading to an increasing stock of shelf-warmers in an online store are described. Afterwards, an indicator measuring the tendency of a good to be a shelf-warmer is developed. Following this, methods for reducing the stock of shelf-warmers are presented 
and the results of an experiment conducted in a real business environment are described. The last part of the paper presents conclusions.

\section{The causes of an increasing stock of shelf-warmers in an online store}

Compared to traditional trade, electronic commerce has specific characteristics and features. Therefore, the key factors causing an increasing stock of shelfwarmers can be classified into two groups (Chodak 2016a). The first group is related to trade in general, whereas the second is associated with the specific environment of e-commerce.

\subsection{General reasons}

The most important factors of the formation of slow moving inventory are incorrect demand forecasts and improper inventory control.

The subjects of demand forecasting and inventory control have been analysed for many decades. Croston (1974) drew attention to the unnecessarily high stocks that result from using inaccurate forecasts. Croston's method of stock control is based on stochastic models for the forecasting of intermittent demand (Shenstone and Hyndman 2005) and may improve inventory control in some cases. Sani and Kingsman (1997) searched for optimal methods of periodic inventory control and demand forecasting for low demand items. They concluded that for very low demands, below 20 units per year, Naddor's heuristic (1980) is optimal both for reducing costs and maintaining service quality. Schultz (1987) considered decision rules for controlling the inventory of SKUs (stock keeping units) with lumpy demand. While forecasting methods based on exponentially weighted moving averages (EWMA) are often efficient for fast moving SKUs, the over-stocking of slow moving products may occur (Johnston and Boylan 1996). The inventory management of SKUs with lumpy demands is a highly problematic task. Mak et al. (1999) proposed a mathematical model for determining the optimal replenishment policies for such slow moving products. Kim et al. (2008) developed a method for forecasting and modelling product demand for a slow moving product. Their method includes calculating the average rate of sales (ARS) for a product from historical data on demand and, if the product is a slow moving product, by modifying the ARS using the GARCH (Generalized Autoregressive Conditional Heteroscedasticity) method to model the expected demand and variability in demand for a slow moving product.

It should also be mentioned that incorrect product assortment planning (PAP) is an important factor in the formation of unwanted inventory (Mahajan and Van Ryzin 2001; Mantrala et al. 2009).

Inappropriate pricing policies are another cause of unwanted inventory. Based on the laws of demand for normal products, increasing prices may lead to low 
demand. In electronic commerce, the relative ease with which prices can be compared causes a higher price elasticity of demand and thus higher prices may significantly decrease product sales (Brynjolfsson and Smith 2000; Granados et al. 2012).

Another reason for the existence of shelf-warmers is related to the end of a product's life cycle and its replacement by a newer generation of products on the market. This is especially true for products with a short life cycle (Kurawarwala and Matsuo 1996).

\subsection{Reasons connected with the environment of e-commerce}

There is an abundant literature on intermittent demand and inappropriate inventory control. However, there is a research gap concerning slow moving products in online stores. For this reason, the key factors leading to an increase in the stock of shelfwarmers in e-shops will be discussed more widely.

A major factor, specific to the environment of e-commerce, is the large number of items that can be offered in an online store, the so-called long tail (the concept of a long tail in Internet trade was popularized by Anderson (2006)). The reasons for a long tail in an online store result from three distinguishing features of electronic commerce (Chodak 2014):

- The two-step sales process (the product ordered by a customer does not have to be physically available in the online store's warehouse),

- The very low cost of presenting a product in a virtual environment (in contrast to traditional trade in which there are limits on the number of items offered, due to the high cost of exhibition space),

- Efficient search engines, which enable a customer to quickly find the product required, even amongst a very large number of items.

In bricks-and-mortar retail, models for optimizing the assortment deal with a setting in which shelf-space limits the total inventory and shelf-space allocation determines the limits on the inventory level of each product (Kök and Fisher 2007). In electronic commerce, there are various models of inventory management that enable keeping various levels of the assortment in stock (e.g. drop-shipping models, or other methods for logistic outsourcing, such as third or fourth party logistics models - 3PL, 4PL (Selviaridis and Spring 2007).

The wide range of products in an online store leads to an increase in potential demand. Optimisation of various search engines enables an online store with a large number of products to attract a large number of customers. However, offering a long tail of products delivered by various suppliers may require ordering a quantity of slow moving items that exceeds current demand, due to the minimum order quantity (MOQ) set by the supplier (Zhu et al. 2015). For example, a customer may order only one unit, but the MOQ set by a supplier is ten units. Thus nine units may become shelf-warmers waiting for an order. If this problem of excess units exists for 
a large number of SKUs, it will significantly increase inventory levels and decrease the liquidity of a company.

An important factor distinguishing e-commerce from traditional trade is the lack of a need to maintain costly exhibition space. Warehousing costs are much lower without the necessity of exhibition space in commercially attractive locations. This factor may result in lower pressure on inventory control. Online store managers may not pay sufficient attention to inventory policy, paying more attention to the best sellers while not optimizing the inventory of slow moving SKUs.

Another cause of an increasing stock of shelf-warmers in online stores is the heterogeneity of online shoppers, due to the absence of geographical constraints. Such a variety of customers may increase the range of assortment offered, in order to satisfy different interests and tastes (Fang et al. 2016). On the other hand, the variability of the online environment may lead to a shelf-warmer becoming demanded by many customers in a relatively short space of time (for example, a niche book popularized by a blogger or other social media influencer).

The inventory level decreases not only due to demand, but also increases due to returns (de Brito and Dekker 2003). The problem of product returns in e-commerce is much more important than in traditional trade, due to the fact that the client cannot have physical contact with a product before it is purchased. Therefore, the return policies given by an online store should be customer friendly (Srinivasan et al. 2002) and in accordance with legal requirements. In most countries, the legal regulations on online sales allow customers to return goods to an e-shop without giving any reason. In some cases, the percentage of returns may be as high as 30-40\% of online store sales (Pyke et al. 2001). Therefore, frequent customer returns can cause an increase in the stock of shelf-warmers. The problem of returns is not uniform over e-commerce sectors. The percentage of returns is especially high in the clothing sector (Ramanathan 2011).

It is also worth mentioning that shelf-warmers can also exist in traditional trade. One reason for the existence of unwanted shelf-warmers may be new product groups of which the public is not aware. Expanding the assortment with new products results in the difficulty of estimating future demand (Crawford 2008). New products face the so-called problem of a "cold start" in recommendation systems, which are very important in creating online sales (Liu et al. 2014). Poorly selling, and even non-rotating items of new goods generate growing stocks.

The reasons mentioned above, summarized in Fig. 1, lead to an increasing stock of shelf-warmers in an online store. These reasons hold not only for classical online retailers, which buy products from suppliers and sell to customers, but also for D2C (direct-to-consumer) and B2B (business-to-business) online shops. Consequently, there is a need to propose methods for managing this important inventory problem.

\section{An indicator for detecting shelf-warmers}

There are many methods for classifying products in the context of inventory control. Three popular methods (selective inventory control techniques) are usually applied for classifying inventory items (Rabieh et al. 2016; Aktunc et al. 2019): 


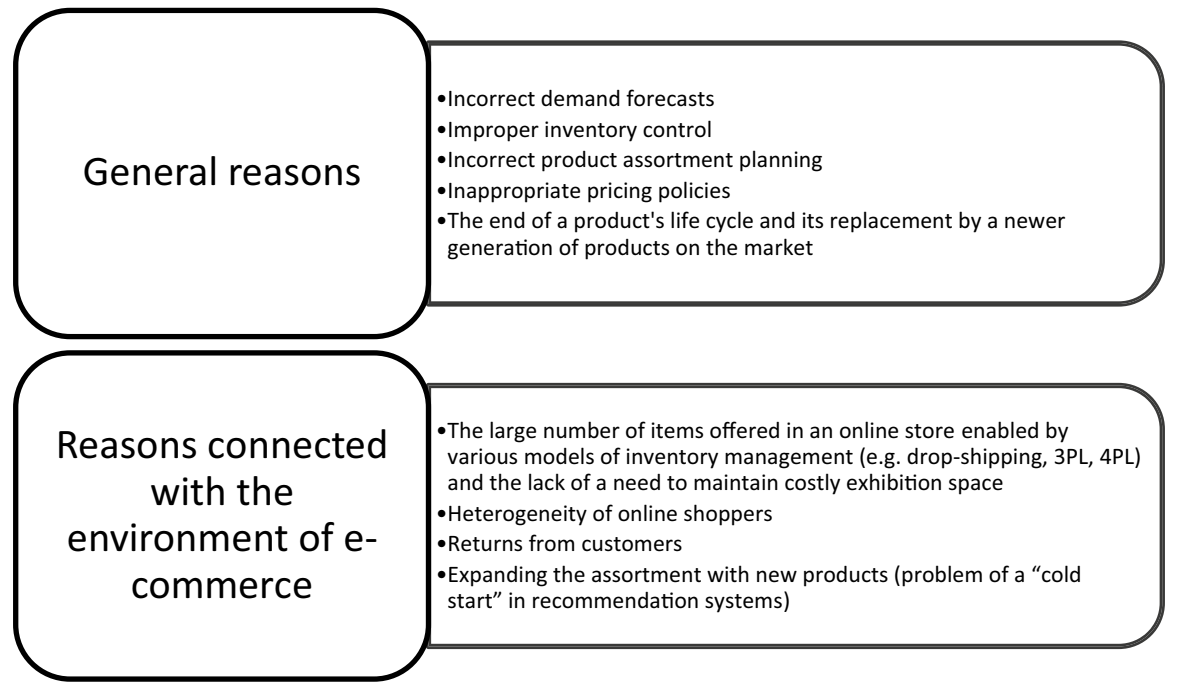

Fig. 1 The causes of an increasing stock of shelf-warmers in an online store

- $\mathrm{ABC}$ analysis, classifies items in terms of annual financial income (High, Medium, Low).

- VED analysis, classifies items in terms of their functional importance (Vital, Essential, Desirable).

- FNS analysis, classifies items in terms of the speed of trading (Fast, Normal, Slow).

When a large number of SKUs are in stock (e.g. more than ten thousand), assessment of which products are shelf-warmers should be carried out using automated analytical tools. In order to determine the shelf-warmers among a large set of SKUs, the indicator (1) is proposed. Applying such a tool provides important data from the point of view of optimizing inventory costs. This indicator ( $S W-$ Shelf-warmer), can be used in a procedure which highlights goods that have remained in stock for too long.

In defining the proposed indicator, we assume that the FIFO method (first in first out) method for inventory control is used. Formally, the $S W$ indicator for a given product is defined as (Chodak 2016a):

$$
S W=\sum_{n=1}^{N} d_{n} \cdot I_{n}
$$

where: $S W$-indicator used in the assessment of shelf-warmers; $n$-delivery number; $N$ - number of deliveries; the most recent delivery is number $1 ; d_{n}$ - number of days from the $n$-th delivery, in accordance with the FIFO procedure; $I_{n}$-number of items (or value) of product left in stock from the $n$-th delivery.

This indicator can be calculated in both natural units and monetary values. However, in the second case, it is hard to calculate the appropriate value of the indicator 
for a good when the sale price is variable. Also, the purchase price may vary according to delivery, which again complicates the calculations. We therefore suggest the use of natural units when calculating the indicator.

\section{Example}

Assume that the stock level of one product is ten items, originating from two deliveries. Eight items come from the first delivery, which took place 30 days ago, and two items are from the latest delivery, which took place three days ago. For these data, the value of the indicator is 246 , i.e. $(30 \times 8+3 \times 2)$.

A procedure for detecting shelf-warmers should highlight goods that have been lying in stock for a longer time, rather than those currently with a high stock level, but characterized by high turnover. However, this indicator also highlights those products characterized by a high turnover, but inappropriate replenishment policy. Therefore, the values of this indicator should be analysed in two dimensions.

One crucial matter is the evaluation of the appropriate range of this indicator. Firstly, we assume that the items in stock should have come from the most recent delivery. In this case, the value of the indicator is equal to $d_{1} \cdot I_{1}$, where $d_{1}$ is the number of days that have elapsed since the last delivery, and $I_{1}$ is the number of units or value of the items still in stock of a good from the last delivery. If this indicator exceeds $d_{l} I_{l}$, it shows that there are SKUs in stock from earlier deliveries. In such cases, the ordering policy for that good should be revised.

Assessment of the turnover of a good based purely on how many days have elapsed since the last delivery is problematical, because it depends on many factors, such as product type, phase of the product life cycle etc. High values of the indicator may result from the rapid turnover of a good, or simply when a long time has elapsed since the previous delivery. We therefore suggest a procedure for detecting shelf-warmers based on the following three-dimensional vector:

$$
\left(S W_{i}, d_{1 i}, K o P_{i}\right)
$$

where: $S W_{i}$-value of the indicator for the $i$-th product; $d_{1 i}-$ number of days since the last delivery of the $i$-th product. $K o P_{i}$ - denotes the kind of the $i$-th product.

The kind of a product is defined according to how quickly its value declines over time. The stock level of products whose value decreases quickly should be more closely controlled compared to those whose value remains constant (or declines very slowly) over time. This factor can be assessed using a discount factor, which indicates the speed at which the value of the product declines over time. A simpler approach is to divide products into two classes ( $Q D o V$ - quickly declining value, SDoV-slowly declining value). This division can be made on the basis of commodity groups which are each defined as either deteriorating (quickly declining value) or non-deteriorating (slowly declining value).

Products can be classified into eight groups as follows by applying thresholds: 


$$
\begin{aligned}
& S W_{i}>d_{1 i} \cdot I_{1 i}, d_{1 i}>m_{i} \text { and } K o P_{i} \in Q D o V \Rightarrow P_{i} \in Z 1 \\
& S W_{i}>d_{1 i} \cdot I_{1 i}, d_{1 i}<m_{i} \text { and } K o P_{i} \in Q D o V \Rightarrow P_{i} \in Z 2 \\
& S W_{i}=d_{1 i} \cdot I_{1 i}, d_{1 i}>m_{i} \text { and } K o P_{i} \in Q D o V \Rightarrow P_{i} \in Z 3 \\
& S W_{i}=d_{1 i} \cdot I_{1 i}, d_{1 i}<m_{i} \text { and } K o P_{i} \in Q D o V \Rightarrow P_{i} \in Z 4 \\
& S W_{i}>d_{1 i} I_{1 i}, d_{1 i}>m_{i} \text { and } K o P_{i} \in S D o V \Rightarrow P_{i} \in Z 5 \\
& S W_{i}>d_{1 i} I_{1 i}, d_{1 i}<m_{i} \text { and } K o P_{i} \in S D o V \Rightarrow P_{i} \in Z 6 \\
& S W_{i}=d_{1 i} I_{1 i}, d_{1 i}<m_{i} \text { and } K o P_{i} \in S D o V \Rightarrow P_{i} \in Z 8
\end{aligned}
$$

where: $P_{i}-i$-th product; $i$ is the number denoting a SKU (inventory number). $m_{i}$ - threshold value for the number of days elapsed since the date of the last delivery of the $i$-th SKU. $d_{1 i}$ - number of days since the last delivery of the $i$-th SKU. $I_{1 i}$ - number of units of the $i$-th item received in the last delivery. $Z 1, \ldots, Z 8-$ the classification sets describing the SKUs (see Table 1).

In order to determine the threshold value $m$, one may apply the sufficiency ratio $(S R)$. The sufficiency ratio (often called the turnover ratio in the literature (Rao and Rao 2009)), expressed in days, determines the time for which the stock of a product should be sufficient:

$$
S R=\frac{M}{\bar{S}_{d}}
$$

where $M$ - the size of the current inventory of a given SKU; $\bar{S}_{d}$-average daily sales (the ratio of the sales volume to the number of days in the period).

It might be assumed that such a threshold value could be applied to each SKU individually. However, in the case of slowly rotating goods, the denominator can take a value close to 0 (or even 0 , in the case of goods for which there has been no sale at all yet, which means that the expression $S R$ is undefined). Therefore, it seems reasonable to apply average sufficiency ratios, determined according to the class of good ( $Q D o V$ or $S D o V$ ), and use these as the threshold values of $m$. Such a sufficiency ratio is only a proposal for the value of $m$. Other indicators based on the turnover of a product can also be taken into consideration.

If no sale of a product has occurred yet, the criterion for classifying this product as a shelf-warmer is as follows: the number of days from the last delivery exceeds the value $m$ (as defined for the appropriate group of products as a whole).

The classification of products according to the three-dimensional indicator defined above is presented in Table 1.

In the case of items for which the value of the shelf-warmer indicator exceeds the appropriate critical value, it is necessary to implement procedures to reduce the inventory stocks of these items. If, in addition, the value of a product declines quickly, then urgent action is needed. 







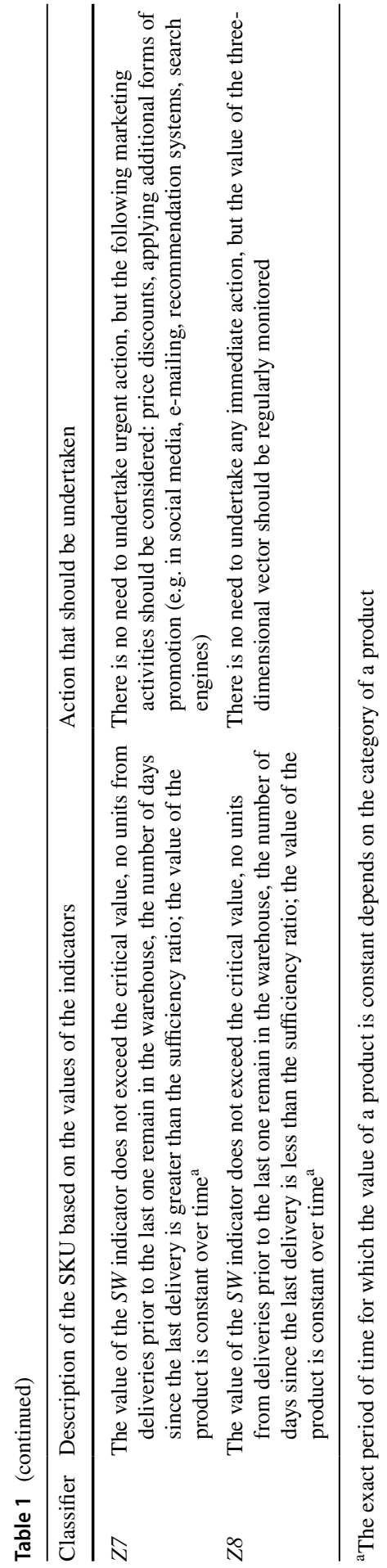




\section{Proposal of a three-stage procedure to reduce the number of shelf-warmers}

The identification of shelf-warmers is important, but this is only one step in the process of improving inventory control. Figure 2 illustrates a three-stage procedure aimed at reducing the level of shelf-warmers. The first step was described in the previous section. The next step is the implementation of methods that reduce the levels of unwanted inventory. The following are examples of standard techniques for reducing the levels of unwanted inventory: price promotions (Gedenk et al. 2006), cross-selling (Kamakura 2008) and bundling goods (Ernst and Kouvelis 1999). In some cases, the policy on the return of goods should be renegotiated with the suppliers (if this is possible).

In the case of high storage costs, scrapping and utilisation are other possibilities for reducing inventory levels. Even if such solutions do not sound pleasant, in some cases they are much cheaper than keeping products in stock.

The issue of selecting the best possible strategy and linking it to the priorities and context of an enterprise have received very limited attention in the academic literature (Syntetos et al. 2010).

In this paper we propose methods for reducing the stocks of shelf-warmers that are appropriate to the environment of e-commerce. The first method is adapting the system of recommendations towards decreasing the levels of unwanted inventory. The second method is based on SEO, and the third method uses social media.

In the case of an online store, a recommendation system is a very important form of promoting goods, e.g. (Schafer et al. 2001; Adomavicius and Tuzhilin 2005; Senecal and Nantel 2004). It should be aimed towards highlighting goods that could be very interesting to a particular customer, as well as reducing the level of unwanted inventory. Suitable combination of these two criteria should not only promote the sale of highly demanded goods, but also reduce the level

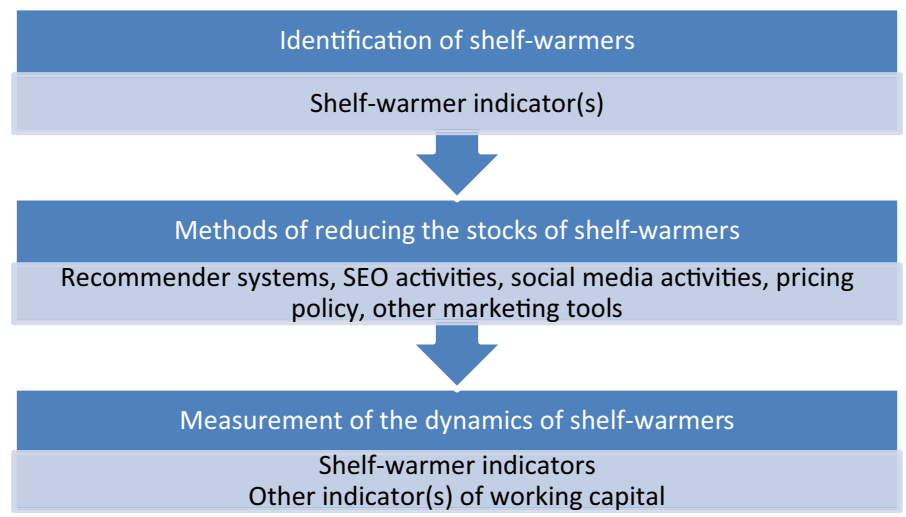

Fig. 2 Description of a three-stage procedure for minimizing the level of stocks of shelf-warmers (Chodak 2016b) 
of unwanted stocks. The following section will present a recommendation system aimed at reducing the level of shelf-warmers in an online store (Chodak and Suchacka 2012).

The general idea of such a system is to highlight products that are both more likely to be purchased by a target customer (i.e. products with a high recommendation score) and generate high inventory costs at the same time. Depending on the specificities of a web store, these two criteria can be appropriately applied or weighted.

For example, the criteria can be used sequentially. In the first step, any recommendation technique can be used to obtain a set of $N$ top recommendations. After this, the inventory costs of a product can be used to order these recommendations. However, we can also use multicriteria analysis. This approach is proposed in this paper.

Two approaches to defining the weights of these two criteria (the recommendation score and the product inventory cost) may be applied. According to one approach, weights are fixed endogenously. However, according to Ramanathan (2006) they can also be automatically generated when the model for such a recommendation system is optimised. In the model proposed here, the weights are partially exogenous. Firstly, a decision maker, e.g. a manager, ascribes a baseline weight $w$ to the recommendation score. This weight is then adjusted by $L V_{i}$, a factor reflecting the inventory cost for the $i$-th product. This approach is adopted for all the SKUs offered by a web store.

The value of the composite recommendation function for the $i$-th SKU in relation to the $j$-th product is calculated according to Eq. 5 (Chodak and Suchacka 2012):

$$
R F_{i j}=L V_{i} \cdot w \cdot Q_{i j \_n o r m}+\left(1-L V_{i} \cdot w\right) \cdot C_{i \_n o r m}
$$

where:

- $R F_{i j}$ is the value of the composite recommendation function for the $i$-th product, used for making a decision on whether to show the $i$-th product together with the $j$-th product or not,

- $L V_{i}$ is the inventory cost factor describing the annual proportional decline in the value of the $i$-th product,

- $w$ is the weight of the recommendation score as established by a manager, $w \in$ $[0,1]$,

- $Q_{i j \_n o r m}$ is the normalized value of the recommendation score $Q_{i j}, Q_{i j \_n o r m} \in[0$, 1],

- $C_{i \_n o r m}$ is the normalized value of the inventory costs for the $i$-th product, $C_{i \_n o r m}$ $\in[0,1]$.

The values of this composite recommendation function are calculated for all pairs of products (this must be done periodically) and stored in a database. Such a recommendation system tends to highlight products with currently high inventory costs and thus facilitates removing them from the warehouse. Products to be presented 
with the $j$-th product will be presented on the web page describing the $j$-th product in a recommendation box, which is usually placed under the description of the product being viewed.

The problem of shelf-warmers in an online store can also be solved in other ways. Taking into account that many visitors come from a search engine, such as Google, it is important to conduct SEO. SEO is the process of creating, formatting and promoting pages in a manner that ensures a high ranking for appropriate keyword phrases when a user performs a web search (Dover and Dafforn 2011). Davis (2006) states that SEO is the art, craft, and science of driving web traffic to web sites and web traffic is food and oxygen to web-based businesses and online stores.

SEO may cover an online store's website in general, but also its products' pages. The analysis of web pages, which is an important tool for an e-businesses in controlling and optimizing its website (Fasel and Zumstein 2009), may be carried out by special software, such as Google Search. The main activities of SEO include the following changes in HTML code (which is created dynamically by e.g. PHP +SQL software):

- Optimization of metatags: <keywords $>$, < description $>,<$ title $>$

- Adding headings $<\mathrm{H} 1>$, $<\mathrm{H} 2>$ etc.

- Optimization of OPEN GRAPH metatags $<$ title $>,<$ description $>$.

- Optimization of a product's description with unique text generated by the copywriter. Original and unique text is always mentioned as a very important factor in improving a page's position in SERP (Search Engine Results Page).

Another important method of decreasing the level of shelf-warmers is the use of social media. There is a very large number of different social media services, but Facebook, Instagram and Youtube are the most popular tools (Killian and McManus 2015; Chaffey 2020). These sites may be used in the process of reducing unwanted inventory. Facebook is the most popular social medium at present, but the most effective methods for companies to use it are not clear (Hansson et al. 2013). In the next section, we propose a social media campaign aimed at selling shelf-warmers.

The last step of the proposed three-stage procedure (Fig. 2) is the measurement of the dynamics of shelf-warmers. This step aims to assess whether the methods applied to reduce unwanted inventory are efficient or not. This topic will not be analysed more deeply, as there is a considerable literature about liquidity indicators in the context of working capital e.g. (Richards and Laughlin 1980; Michalski 2009; Ebben and Johnson 2011).

\section{Experiment in an online store}

The problems of slow moving products and products that are never sold even once are crucial for most Internet shops. We conducted an experiment in a real specialist Internet shop. The managers of this shop indicated that shelf-warmers are a significant problem and therefore accepted the proposal of undertaking an experiment aimed at lowering the stocks of unwanted inventory. 


\subsection{Design of the experiment}

The experiment started on the 19th of February, 2019. All changes to the web pages were finished on the 20th of February. Due to the large number of changes required, it took two days to carry out the coding. The data for this experiment were collected for almost 10 months, until the 17th of December and measurements were made in five stages (days). The lengths of time between the individual measurements are not uniform, because collection of the sales data required access to the e-shop's databases and statistics. The manager who had access to the database of this online store often lacked the necessary time to collect and share data.

In the first step of the experiment, 160 products were selected from the list of products that had not been sold even once. These products met the following two conditions:

1. They had been in stock for over 2 years and no items had been sold (the products in stock had "warmed the shelf" for at least 1031 days).

2. The list did not contain any seasonal products to avoid distorting the results;

The 160 oldest products that satisfied these conditions were chosen for the analysis.

Such products can be called shelf-warmers and remain a problem and a source of unnecessary costs for the e-store. The smallest value of the $S W$ indicator for these products was 1031 (this is the minimum time spent in stock) and the largest value was 12,929 .

In the next step, these 160 products were divided into eight groups-each containing 20 products.

In each group we conducted one or more of the changes described below to improve the visibility of the products to search engines or promote them, either on Facebook or directly on the e-shop website.

To carry out SEO, we conducted the following activities:

(1) we added a $<\mathrm{H} 1>$ header to the product description with the name of the product. This should improve the rank of a product in the search engine results.

(2) we changed the description of the product using a unique text generated by the copywriter.

(3) we modified the metatags: $<$ title $>,<$ description $>,<$ keywords $>$ and also the OPEN GRAPH metatags <title $>$, < description $>$. Changes in the metatags, in particular adding important keywords (which were proposed by the copyrighter and an SEO expert) should also improve the product's rank in SERP.

To promote products on the e-shop website, we:

(1) Added ISBN (International Standard Book Number) identifiers to the product descriptions (to promote products in the Google Merchant System). 
(2) Reduced the prices of chosen products by $20 \%$. These products are also presented in the category "Price reductions".

(3) Added one group of products to the category "We recommend" in the online store. This is a category containing the products recommended to customers.

To promote products using Facebook, we created one post for each product with a photo, description and link to the e-shop.

The promotional activities applied in each of the eight groups of shelf-warmers are as follows:

(1) Added a $<\mathrm{H} 1>$ header;

(2) Price reduction of $20 \%$;

(3) Placement on Facebook;

(4) Added the ISBN identifier;

(5) Added unique text to the description;

(6) Placement in the category "We recommend";

(7) Modification of the metatags;

(8) All the above changes.

\subsection{Results of the experiment}

As can be seen in Table 2, the best results were obtained in the group where all the changes were implemented, which is what we would expect to happen (55\% of the items sold). A good result was also obtained amongst the products advertised on Facebook- $40 \%$ of the items sold. In each of the following groups of products: (a) $20 \%$ price reduction, (b) unique text added to the description and (c) placement in the category "We recommend"; $35 \%$ of the items were sold, which can be treated as a good result. In the group where a $<\mathrm{H} 1>$ header was added with the name of the product, $30 \%$ of the items were sold, which is quite a good result considering

Table 2 Number of items sold in each group of products

\begin{tabular}{|c|c|c|c|c|c|c|c|}
\hline \multirow[t]{2}{*}{$\begin{array}{l}\text { Number } \\
\text { of group }\end{array}$} & Changes & $\begin{array}{l}18 \text { th } \\
\text { April } \\
2019\end{array}$ & $\begin{array}{l}29 \text { th } \\
\text { June } \\
2019\end{array}$ & $\begin{array}{l}\text { 2nd } \\
\text { September } \\
2019\end{array}$ & $\begin{array}{l}15 \text { th } \\
\text { October } \\
2019\end{array}$ & $\begin{array}{l}17 \text { th } \\
\text { December } \\
2019\end{array}$ & $\sum$ \\
\hline & & \multicolumn{6}{|c|}{ Measurement dates } \\
\hline 1. & Added $\mathrm{a}<\mathrm{H} 1>$ header & 2 & 1 & 1 & 1 & 1 & 6 \\
\hline 2. & Price reduction of $20 \%$ & 0 & 1 & 3 & 3 & 0 & 7 \\
\hline 3. & Placement on Facebook & 2 & 2 & 1 & 0 & 3 & 8 \\
\hline 4. & Added the ISBN identifier & 0 & 1 & 1 & 1 & 0 & 3 \\
\hline 5. & $\begin{array}{l}\text { Added unique text to the } \\
\text { description }\end{array}$ & 2 & 3 & 1 & 1 & 0 & 7 \\
\hline 6. & $\begin{array}{l}\text { Placement in the category "We } \\
\text { recommend" }\end{array}$ & 1 & 3 & 2 & 1 & 0 & 7 \\
\hline 7. & Modification of the metatags & 2 & 1 & 0 & 1 & 0 & 4 \\
\hline 8. & All the above changes & 1 & 4 & 4 & 2 & 0 & 11 \\
\hline
\end{tabular}


the very low cost of such changes. These can be implemented automatically using a simple SQL query.

The worst result amongst all the groups (15\% of items sold) was obtained by the group where just the ISBN identifier was added. This was expected, as it is rather a small change that may simply influence the Google Merchant to present a product more often. Also, the modification of metatags lead to only $20 \%$ of items being sold, which suggests that SEO changes should be comprehensive, i.e. addition of both a header and a unique description. But even in these cases, the results are surprisingly good, taking into consideration that the changes are very small.

From these results, considering that these products were clear shelf-warmers, we can conclude that all these marketing activities achieved more than satisfactory results. Without these changes, the goods could have remained on the shelves for a number of years.

Table 3 presents the Pearson correlation coefficient calculated pairwise for each of group of products. This can be used to indicate differences in how the changes affect the profile of sales over time. For example, suppose one change has a rapid effect on sales that dies out, while another change has a more long-term effect. The sales figures for these two changes will be negatively correlated. We are aware that for such a small number of measurements $(N=5)$, statistical significance (in this case calculated using the $p$ value) will be difficult to attain and such a correlation needs to be appropriately interpreted. In addition, the level of sales is low (by definition), which makes interpretation difficult. The sales profiles of the goods subject to price reductions of $20 \%$ and of those placed on Facebook were significantly negatively correlated (Pearson_correlation $=-0.896 ; p$ value $=0.039$ ). Investigation of the sales figures indicates that placement on Facebook works more quickly than reducing the price. On the other hand, at the end of the study period there is a jump in sales of the goods advertised on Facebook. This might be related to the effectiveness of Facebook in promoting pre-christmas sales, but due to the limited nature of this study, more research is necessary. The second statistically significant correlation occurred between groups in the category "We recommend" and "all the above changes" (Pearson_correlation $=0.932 ; p$ value $=0.021$ ). This indicates that the sales profiles over time of these two groups were very similar. Such positive correlations involving the group subject to "all the above changes" and other effective techniques should be fairly common, since the underlying profile of sales in the "all the above changes" group will be the resultant of the effects of each change.

As can be seen in Table 4, after 10 months over 33\% of the shelf-warmers had been sold. In the group of 20 products where all the changes were implemented, over $50 \%$ of the items were sold. This result was surprising to the e-shop managers and the author of the experiment. The initial results of the experiment were so promising that managers ordered to promote all the shelf-warmers. Unfortunately, this made it impossible to compare the results with a standard control group in which no changes were made. We expected that our changes would lead to selling 10-15\% of the items analysed. Taking into consideration that these products had been lying in stock for almost 3 years, selling almost one-third of them without implementing an expensive marketing campaign is a really good result. This shows that low budget 


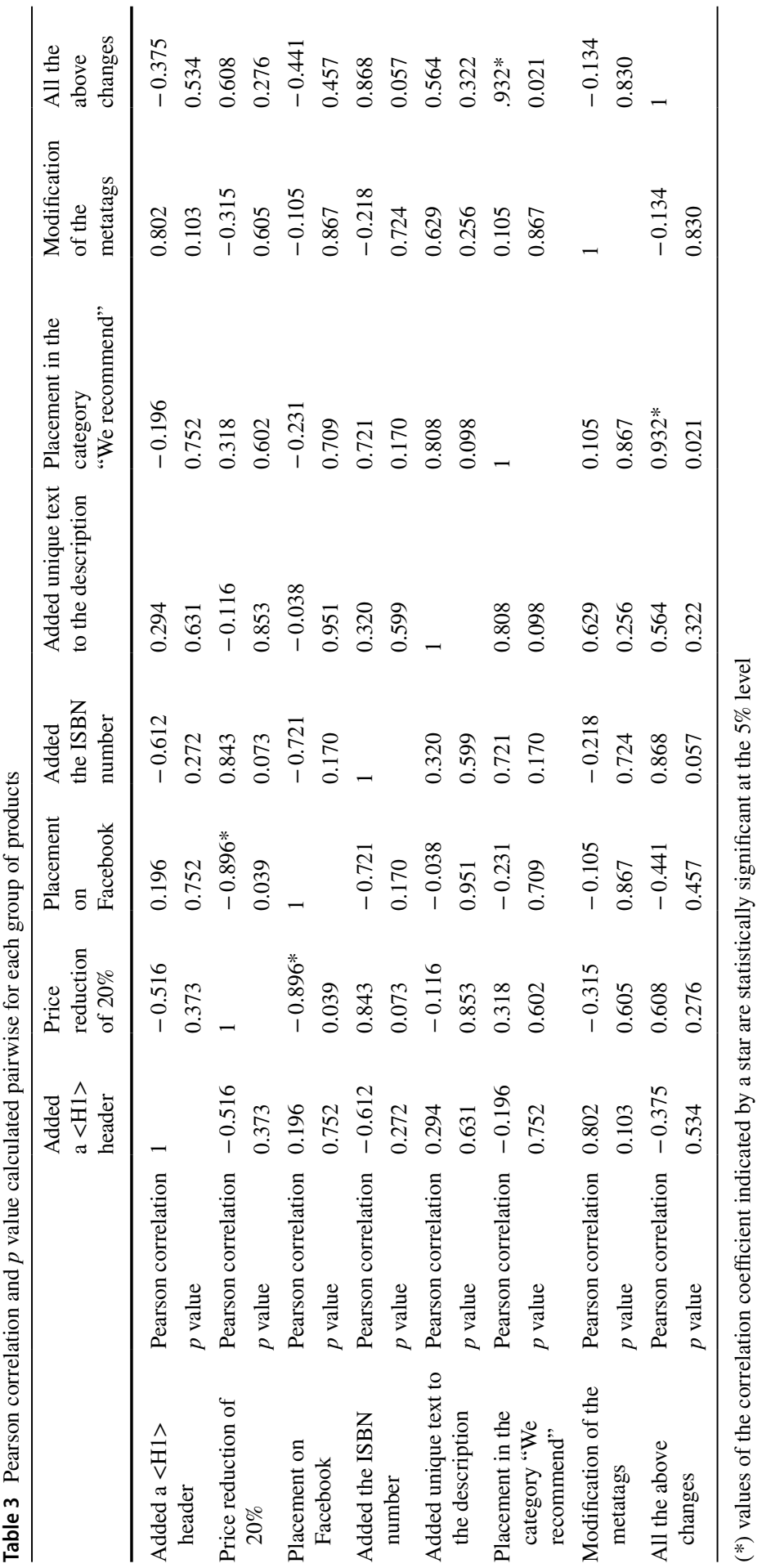


Table 4 Total number of items sold as a percentage of all of the items in the sample

\begin{tabular}{lcc}
\hline Date & Number of items sold & $\begin{array}{c}\text { Percentage } \\
\text { of all items }\end{array}$ \\
\hline 18.04 .2019 & 10 & $6.25 \%$ \\
29.06 .2019 & 16 & $10.00 \%$ \\
02.09 .2019 & 13 & $8.13 \%$ \\
15.10 .2019 & 10 & $6.25 \%$ \\
17.12 .2019 & 4 & $2.50 \%$ \\
$\sum$ & 53 & $33.13 \%$ \\
\hline
\end{tabular}

activities, such as SEO improvements and social media posts, may help to solve the problem of shelf-warmers.

As can be seen (Table 4), the overall number of items sold initially increased before falling, but still remained significant. In the last period, three of the products advertised on Facebook were sold. This suggests that social media activities may result in long run benefits (especially for niche products). One may also conclude that in e-commerce the search engine does not react immediately to changes. The effects of SEO and social media activities may possibly be still visible after a few months or come only after few months.

\section{Summary}

Slow moving products represent a key problem in the management of online stores with a large number of stock keeping units. The various factors leading to the ever increasing number of shelf-warmers in e-shops described in this paper show that this phenomenon may occur more often in e-commerce than in traditional bricksand-mortar trade. Slow moving SKUs can increase the overall inventory cost of an online store. Therefore, the approach to shelf-warmer detection described here seems to be an appropriate device for inventory optimization, which can be used by e-commerce managers. Identification of such problematic products is very important in the context of appropriate inventory control. The proposed approach enables inventory managers to find products with inappropriate inventory levels. Such products lower the liquidity of a company and therefore, the policy for controlling their inventory should be changed. A three-stage procedure for dealing with shelfwarmers was presented. This approach enables an inventory manager to decrease the levels of the most costly and unwanted stocks. One possible method may be applying a recommendation system aimed at reducing the level of shelf-warmers in an online store. SEO activities and the use of social media can improve the liquidity of an e-shop by decreasing the levels of expensive stock. The results of the experiment show that even inexpensive SEO activities and social media posts (on Facebook in this case) are efficient tools in decreasing the levels of unwanted inventory. The best results were obtained by combining promotional activities, such as improving product descriptions and metatags, social media posts, price reductions and 
promoting products by presenting recommendations online. The experiment shows that even simple and inexpensive improvements may result in decreasing the levels of unwanted inventory. Over $33 \%$ of the shelf-warmers that had been in store for over 3 years were sold over the course of 10 months. The results obtained are significant. Nevertheless, online stores should take into account the causes of shelfwarmer formation when choosing methods for dealing with this problem.

Based on the results obtained, the recommendations to online retailers are as follows: the identification of shelf-warmers needs to be done at least once per month (more frequent control is needed if the share of shelf-warmers is relatively high, e.g. over $5 \%$ of all inventory). SEO activities, such as metatag modification, adding headers $\langle\mathrm{H} 1>$ and unique texts for all shelf-warmers, are advisable. Additional activities, such as posting in social media (Facebook, Instagram) and price discounts, are needed. If possible, the recommendation system used by an online store should also take into consideration shelf-warmers, as presented in the proposed model. Returns to suppliers (if possible) should also be considered. If these actions make no effect, additional means of marketing are required to lower the number of shelf-warmers, such as: Search Engine Marketing (SEM), e.g. Google Ads, e-mailing campaigns or other forms of digital marketing. Also, other distribution channels should be considered, e.g. sales on market places such as Amazon, Allegro or Ebay. However, before implementing such activities and/or additional distribution channels, one should first calculate whether the potential advantages from sold items covers the costs of marketing campaigns, commission paid to platforms and other additional costs.

The proposed set of methods of dealing with shelf-warmers in online stores is assumed to be independent of the shop's sector. However, to confirm their effectiveness, such experiments should be carried out in a number of e-shops from various sectors. Further research may include testing the shelf-warmer indicator and methods for decreasing the number of such items for a diverse sample of e-shops.

Acknowledgements The author thanks David Ramsey for help and advice in the final editing of this paper.

Funding This work was partially supported by the National Science Centre (NCN) in Poland under Grant Number: 2018/29/B/HS4/02857.

\section{Compliance with ethical standards}

Conflict of interest The author declares that have no conflict of interest.

Open Access This article is licensed under a Creative Commons Attribution 4.0 International License, which permits use, sharing, adaptation, distribution and reproduction in any medium or format, as long as you give appropriate credit to the original author(s) and the source, provide a link to the Creative Commons licence, and indicate if changes were made. The images or other third party material in this article are included in the article's Creative Commons licence, unless indicated otherwise in a credit line to the material. If material is not included in the article's Creative Commons licence and your intended use is not permitted by statutory regulation or exceeds the permitted use, you will need to obtain permission directly from the copyright holder. To view a copy of this licence, visit http://creativecommons.org/licen ses/by/4.0/. 


\section{References}

Adomavicius G, Tuzhilin A (2005) Toward the next generation of recommender systems: a survey of the state-of-the-art and possible extensions. IEEE Trans Knowl Data Eng 17(6):734-749. https://doi. org/10.1109/tkde.2005.99

Aktunc EA., Basaran M, Ari G, Irican M, Gungor S (2019). Inventory control through ABC/XYZ analysis. In: Industrial engineering in the big data era. Springer, Cham, pp 175-187. https://doi. org/10.1007/978-3-030-03317-0_15

Anderson Ch (2006) Long tail. Why the future of business is selling less of more. Hyperion, New York

Brynjolfsson E, Smith MD (2000) Frictionless commerce? A comparison of Internet and conventional retailers. Manag Sci 46(4):563-585. https://doi.org/10.1287/mnsc.46.4.563.12061

Chaffey D (2020) Global social media research summary 2020, https://www.smartinsights.com/socia 1-media-marketing/social-media-strategy/new-global-social-media-research/. Accessed 15 Nov 2019

Chodak G (2014) Wybrane zagadnienia logistyki w sklepach internetowych: modele, badania rynku (ang. The selected areas of logistic management in e-shops - models and market research), Wroclaw, Publishing House of the Wroclaw University of Science and Technology

Chodak G (2016a) Inventory control in online store-the problem of "shelf warmers". Hradeckie Ekonomickie Dni, Hradec Kralove

Chodak G (2016b) The nuisance of slow moving products in electronic commerce. Prof Center Bus Res 3(2):11-16

Chodak G, Suchacka G (2012) Cost-oriented recommendation model for e-commerce. In: Computer networks. Springer, Berlin, pp 421-429. https://doi.org/10.1007/978-3-642-31217-5_44

Crawford CM (2008) New products management. Tata McGraw-Hill Education, New York

Croston JD (1974) Stock levels for slow moving items. Oper Res Q 25(1):123-130. https://doi. org/10.1057/jors.1974.12

Davis H (2006) Search engine optimization. O’Reilly Media, Inc., Newton

de Brito MP, Dekker R (2003) Modelling product returns in inventory control—exploring the validity of general assumptions. Int J Prod Econ 81:225-241. https://doi.org/10.1016/S0925-5273(02)00275-X

Dover D, Dafforn E (2011) Search engine optimization (SEO) secrets. Wiley, Hoboken

Ebben JJ, Johnson AC (2011) Cash conversion cycle management in small firms: relationships with liquidity, invested capital, and firm performance. J Small Bus Entrep 24(3):381-396. https://doi. org/10.1080/08276331.2011.10593545

Ernst R, Kouvelis P (1999) The effects of selling packaged goods on inventory decisions. Manag Sci 45(8):1142-1155. https://doi.org/10.1287/mnsc.45.8.1142

Fang J, Wen C, George B, Prybutok VR (2016) Consumer heterogeneity, perceived value, and repurchase decision-making in online shopping: The role of gender, age, and shopping motives. J Electron Commer Res 17(2):116

Fasel D, Zumstein D (2009) A fuzzy data warehouse approach for web analytics. In: World summit on knowledge society. Springer, Berlin, pp 276-285. https://doi.org/10.1007/978-3-642-04754-1_29

Gaur V, Fisher ML, Raman A (2005) An econometric analysis of inventory turnover performance in retail services. Manag Sci 51(2):181-194. https://doi.org/10.1287/mnsc.1040.0298

Gedenk K, Neslin SA, Ailawadi KL (2006) Sales promotion. In: Retailing in the 21st century. Springer, Berlin, pp 345-359

Granados N, Gupta A, Kauffman RJ (2012) Online and offline demand and price elasticities: evidence from the air travel industry. Inf Syst Res 23(1):164-181. https://doi.org/10.1287/isre.1100.0312

Hansson L, Wrangmo A, Solberg Søilen K (2013) Optimal ways for companies to use Facebook as a marketing channel. J Inf Commun Ethics Soc 11(2):112-126. https://doi.org/10.1108/JICES -12-2012-0024

Johnston FR, Boylan JE (1996) Forecasting for items with intermittent demand. J Oper Res Soc. https:// doi.org/10.1057/jors.1996.10

Jollyta D, Gusrianty G, Sukrianto D (2019) Analysis of slow moving goods classification technique: random forest and Naïve Bayes. Khazanah Informatika: Jurnal Ilmu Komputer dan Informatika. https:// doi.org/10.23917/khif.v5i2.8263

Kamakura WA (2008) Cross-selling: offering the right product to the right customer at the right time. J Relat Mark 6(3-4):41-58. https://doi.org/10.1300/J366v06n03_03 
Killian G, McManus K (2015) A marketing communications approach for the digital era: managerial guidelines for social media integration. Bus Horiz 58(5):539-549. https://doi.org/10.1016/j.busho r.2015.05.006

Kim E, Vorsanger JP, Chan S, Islam S (2008) U.S. Patent Application No. 11/565,685

Kök AG, Fisher ML (2007) Demand estimation and assortment optimization under substitution: methodology and application. Oper Res 55(6):1001-1021. https://doi.org/10.1287/opre.1070.0409

Kurawarwala AA, Matsuo H (1996) Forecasting and inventory management of short life-cycle products. Oper Res 44(1):131-150. https://doi.org/10.1287/opre.44.1.131

Lewis CD (1997) Demand forecasting and inventory control: a computer aided learning approach. Routledge, New York

Liu JH, Zhou T, Zhang ZK, Yang Z, Liu C, Li WM (2014) Promoting cold-start items in recommender systems. PLoS ONE 9(12):e113457. https://doi.org/10.1371/journal.pone.0113457

Mahajan S, Van Ryzin G (2001) Stocking retail assortments under dynamic consumer substitution. Oper Res 49(3):334-351. https://doi.org/10.1287/opre.49.3.334.11210

Mak KL, Wong YS, Huang GQ (1999) Optimal inventory control of lumpy demand items using genetic algorithms. Comput Ind Eng 37(1):273-276. https://doi.org/10.1016/S0360-8352(99)00072-8

Mantrala MK, Levy M, Kahn BE, Fox EJ, Gaidarev P, Dankworth B, Shah D (2009) Why is assortment planning so difficult for retailers? A framework and research agenda. J Retail 85(1):71-83. https:// doi.org/10.1016/j.jretai.2008.11.006

Michalski G (2009) Inventory management optimization as part of operational risk management. Econ Comput Econ Cybern Stud Res 4:213-222

Naddor E (1980) An analytic comparison of two approximately optimal (s, S) inventory policies. Technical Report 330, Department of Mathematical Science, Johns Hopkins University, Baltimore

Porras E, Dekker R (2008) An inventory control system for spare parts at a refinery: an empirical comparison of different re-order point methods. Eur J Oper Res 184(1):101-132. https://doi.org/10.1016/j. ejor.2006.11.008

Pyke DF, Johnson ME, Desmond P (2001) E-fulfillment. Supply Chain Manag Rev 27:26-32

Rabieh M, Soukhakian MA, Shirazi ANM (2016) Two models of inventory control with supplier selection in case of multiple sourcing: a case of Isfahan steel company. J Ind Eng Int 12(2):243-254. https://doi.org/10.1007/s40092-016-0145-y

Ramanathan R (2006) ABC inventory classification with multiple-criteria using weighted linear optimization. Comput Oper Res 33(3):695-700. https://doi.org/10.1016/j.cor.2004.07.014

Ramanathan R (2011) An empirical analysis on the influence of risk on relationships between handling of product returns and customer loyalty in E-commerce. Int J Prod Econ 130(2):255-261. https://doi. org/10.1016/j.ijpe.2011.01.005

Rao CM, Rao KP (2009) Inventory turnover ratio as a supply chain performance measure. Serb J Manag 4(1):41-50

Richards VD, Laughlin EJ (1980) A cash conversion cycle approach to liquidity analysis. Financ Manag. https://doi.org/10.2307/3665310

Sani B, Kingsman BG (1997) Selecting the best periodic inventory control and demand forecasting methods for low demand items. J Oper Res Soc 48(7):700-713. https://doi.org/10.1057/palgrave. jors. 2600418

Schafer JB, Konstan JA, Riedl J (2001) E-commerce recommendation applications. Data Min Knowl Disc 5(1-2):115-153

Schultz CR (1987) Forecasting and inventory control for sporadic demand under periodic review. J Oper Res Soc. https://doi.org/10.1057/jors.1987.74

Selviaridis K, Spring M (2007) Third party logistics: a literature review and research agenda. The International Journal of Logistics Management 18(1):125-150

Senecal S, Nantel J (2004) The influence of online product recommendations on consumers' online choices. J Retail 80(2):159-169. https://doi.org/10.1016/j.jretai.2004.04.001

Shenstone L, Hyndman RJ (2005) Stochastic models underlying Croston's method for intermittent demand forecasting. J Forecast 24(6):389-402. https://doi.org/10.1002/for.963

Snyder R (2002) Forecasting sales of slow and fast moving inventories. Eur J Oper Res 140(3):684-699. https://doi.org/10.1016/S0377-2217(01)00231-4

Srinivasan SS, Anderson R, Ponnavolu K (2002) Customer loyalty in e-commerce: an exploration of its antecedents and consequences. J Retail 78(1):41-50. https://doi.org/10.1016/S0022-4359(01)00065 $-3$ 
Syntetos AA, Babai MZ, Davies J, Stephenson D (2010) Forecasting and stock control: a study in a wholesaling context. Int J Prod Econ 127(1):103-111. https://doi.org/10.1016/j.ijpe.2010.05.001

Transformers Wiki-Definition of Shelf-warmer. Retrieved from https://fwiki.net/wiki/Shelfwarmer. Accessed 5 Jan 2020

Williams TM (1983) Stock control with Sporadic and Slow-Moving Demand. Journal of the Operations Research Society 35(10):201-206. https://doi.org/10.1016/j.ijpe.2010.05.001

Zhu H, Liu X, Chen YF (2015) Effective inventory control policies with a minimum order quantity and batch ordering. Int J Prod Econ 168:21-30. https://doi.org/10.1016/j.ijpe.2015.06.008

Publisher's Note Springer Nature remains neutral with regard to jurisdictional claims in published maps and institutional affiliations. 